World Maritime University

The Maritime Commons: Digital Repository of the World Maritime University

\title{
Engineering routine remedial work in manned machinery spaces ship: challenge for maritime autonomous surface ships
}

\author{
Emi Yutaka \\ Japan Agency of Maritime Education and Training for Seafarers \\ Nakajima Atsuki \\ Japan Agency of Maritime Education and Training for Seafarers
}

Follow this and additional works at: https://commons.wmu.se/imla2021

Part of the Education Commons

\section{Recommended Citation}

Yutaka, E. \& Atsuki, N. (2021). Engineering routine remedial work in manned machinery spaces ship: challenge for maritime autonomous surface ships. In Pazaver, A., Manuel, M. E., Bolmsten, J., Kitada, M., Bartuseviciene, I. (Eds.), Proceedings of the International Maritime Lecturers' Association. Seas of transition: setting a course for the future (pp. 199-204). World Maritime University. http://dx.doi.org/ $10.21677 /$ imla2021.23

This Paper is brought to you courtesy of Maritime Commons. Open Access items may be downloaded for noncommercial, fair use academic purposes. No items may be hosted on another server or web site without express written permission from the World Maritime University. For more information, please contact library@wmu.se. 
http://dx.doi.org/10.21677/imla2021.23

\title{
Engineering routine remedial work in manned machinery spaces ship - challenge for maritime autonomous surface ships
}

\author{
Emi Yutaka \\ Professor, Chief Engineer, Japan Agency of Maritime Education and Training for Seafarers, \\ Yokohama, Japan, emi-y5t4@jmets.ac.jp \\ Nakajima Atsuki \\ Onboard Instructor, Second Engineer Japan Agency of Maritime Education and Training for \\ Seafarers, Yokohama, Japan, nakajima-a0c5@jmets.ac.jp
}

\begin{abstract}
In 1987, the Japanese government launched the project "Pioneer ship" which had an automatic control system and operated with only 11 crew members, utilizing multipurpose officers and ratings. The pioneer ship is no longer practical; however, recently the concept of a more sophisticated automation system and much fewer crew in machinery spaces has become even more radical as exemplified by MASS (Maritime Autonomous Surface Ships). As far as conventional manned machinery spaces watch system is concerned, by utilizing the five senses (watching, listening, smelling, touching and tasting), duty engineering officers and ratings not only identify defects which are rarely detected by alarm systems but also deal with any defects when alarm systems detect malfunctions in machinery. Taking the engine crews' operation into account, we need to consider not only how to introduce digitalization to the system but also train seafarers for new competences. In this paper, we categorized defects according to detectable, undetectable, remediable or irremediable cases. Taking the categorized cases into account, we analysed potential solutions for both new engine plant systems and new training systems of Maritime Autonomous Surface Ships.
\end{abstract}

Key words : marine engineer, routine work, maritime autonomous surface ships (MASS)

\section{Introduction}

This paper focuses upon engineering issues for future MASS. Additionally we divided engineering work into two categories: operational work and maintenance work. As far as operational work is concerned, thanks to the installation of unmanned machinery space systems, plenty of operational work such as remote control systems for the main engine as well as propulsion systems has already been automated. However, maintenance work including remedial work has not been automated yet. Thus, taking into account the role of engineers against automation systems, engineering crews always take care of deficiencies in engine plant systems when they find something wrong in the automation systems. Therefore, as automation systems progress, the role of seafarers as redundancy will be more important. In this point of view, before discussing MASS issues for engineering crews, we decided to identify how current engineering crews tackle remedial work when engine crews hear engine alarms and also find deficiencies in the engine plant systems.

\section{Method}


In order to consider marine engineers' knowledge and skills for sophisticated Maritime Autonomous Surface Ships (hereinafter referred to as "MASS"), this paper conducts a fundamental study of remedial routine work done by engineering crews. As shown in Table1, the survey target was the Training Ship Kaiwo Maru (hereinafter T.S. Kaiwo Maru), which was 30 years old at the time. Engine alarms and engine crews' work were analysed over a 91 day voyage, including 38 days at sea, 14 days at anchorage and 39 days in port. During this period, engineering crews heard 592 engine alarms and engaged in 556 operations, including both operational and maintenance work. This data proves that engineering crew must not only deal with alarms but also conduct operational or maintenance work on average once in each watchkeeping period. The frequency of ringing alarms and necessary work made us recognize how busy engineering crews in engine rooms are. Accordingly, in this paper, the term engineer includes electricians because research activities were done based on the Japanese maritime engineering system.

Table 1

Basic data of the T.S. Kaiwo Maru

\begin{tabular}{|l|l|}
\hline Age of vessel during data acquisition & 30 years \\
\hline Terms of data acquisition & from $01 / 04 / 2019$ to 30/06/2019 (91days) \\
\hline Days of port & 39 \\
\hline Days at sea & 38 \\
\hline Days of anchorage & 14 \\
\hline
\end{tabular}

\section{Category of MASS}

In accordance with the definition of the International Maritime Organization, Maritime Safety Committee's regulatory scoping exercise on Maritime Autonomous Surface Ships, the level of MASS is categorized into 4 degrees as shown in Table 2.

Table 2.

Degree of autonomy

\begin{tabular}{|l|l|}
\hline Degree 1 & $\begin{array}{l}\text { Ship with automated processes and decision support: } \\
\text { Seafarers are on board to operate and control shipboard systems and functions. } \\
\text { Some operations may be automated and at times be unsupervised but with } \\
\text { seafarers on board ready to take control. }\end{array}$ \\
\hline Degree 2 & $\begin{array}{l}\text { Remotely controlled ship with seafarers on board: } \\
\text { The ship is controlled and operated from another location. Seafarers are } \\
\text { available on board to take control and to operate the shipboard systems and } \\
\text { functions. }\end{array}$ \\
\hline Degree 3 & $\begin{array}{l}\text { Remotely controlled ship without seafarers on board: } \\
\text { The ship is controlled and operated from another location. There are no } \\
\text { seafarers on board. }\end{array}$ \\
\hline Degree 4 & $\begin{array}{l}\text { Fully autonomous ship: } \\
\text { The operating system of the ship can make decisions and determine actions by } \\
\text { itself. }\end{array}$ \\
\hline
\end{tabular}

\section{Remedial work}

Initially, we divided engineers' work into roughly two types: operational work and maintenance work. Operational work includes, for instance, plant operation, changing fuel oil from heavy oil to marine diesel oil, increasing or decreasing engine speed, adjusting engine 
load, and controlling flow of fluid through operation of valves. Maintenance work falls into three categories as follows:

- Time-Based Maintenance (TBM), which is planned maintenance, as it must be scheduled in advance;

- Condition-Based Maintenance (CBM), which should only be performed when certain indicators show signs of decreasing performance or upcoming failure; and

- Breakdown Maintenance (BM), which is performed on machinery that has broken down and is unusable.

\section{Actual data for work done}

The engineering crew conducts numerous tasks which are mainly concerned with the improvement of the plant condition or machinery symptoms. We categorized all collected alarms and works as follows:

- Plant operation;

- Remedial plant operation;

- Time-Based Maintenance (TBM);

- Condition-Based Maintenance; and

- Breakdown Maintenance.

Concerning "Remedial plant operation", one actual case of remedial plant operation was that the duty engineer changed the blade angle of the propeller manually in order to decrease the load of the main engine because the level of shaft torque had reached alarm point and the running condition of the main engine and its turbo charger had also reached a critical area. The automation system tried to handle the load of the main engine within a safety area but could not due to adverse weather. Table 3 and Figure 1 show the actual data of work done by the engineering crew for 91 days.

\section{Table 3}

Number of operational works and maintenance works over 3 months

\begin{tabular}{|l|l|l|l|l|l|}
\hline $\begin{array}{l}\text { Plant } \\
\text { operation }\end{array}$ & $\begin{array}{l}\text { Remedial } \\
\text { plant } \\
\text { operation }\end{array}$ & TBM & CBM & BM & Total \\
\hline 135 & 13 & 173 & 172 & 63 & 556 \\
\hline
\end{tabular}




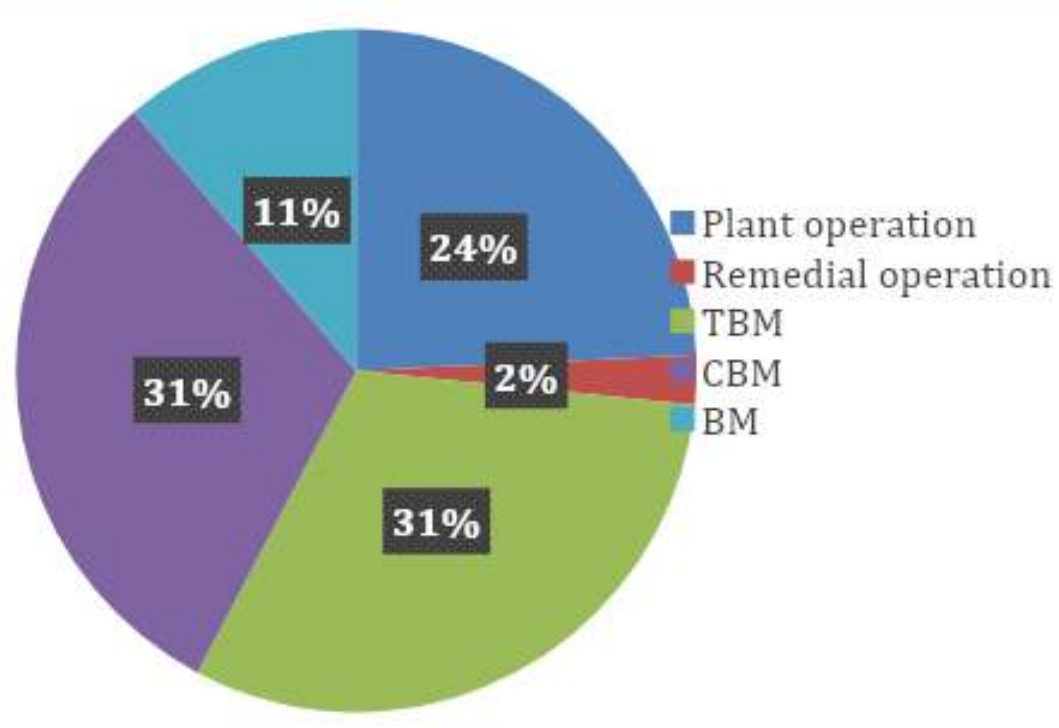

Figure 1. operational work and maintenance work over 3 months

As for the total 63 cases of BM, the majority of cases were leakage (19 cases, 30\%) and electrical problems (17 cases, $27 \%$ ). More than $60 \%$ of leakage problems were caused by gland packing, bonnet packing or flange packing of valves on the steam line and compressed air line. The majority of BM factors were not necessarily related to the ship's age, although T.S. Kaiwo Maru was 30 years old at the time of data collection. Such leakage could easily occur even in a five year old vessel because of expiration of parts such as gland packing or flange packing.

\section{Remedial operation for alarms}

A total of 592 engine alarms were rung in 91 days. These 592 alarms included repetitive alarms, for instance, caused by an electrical problem which often induced repetition. An actual case was the main engine cooling fresh water outlet temperature high alarm ringing 8 times in 4 minutes. The local temperature gauge which is an analogue one showed normal value but the digital gauge frequently detected an abnormal value. Figure 2 shows types of alarms. Alarms are categorized into 3 types: abnormal (295 times), error (64 times) and inevitable (233 times). Abnormal means real malfunction of machinery or equipment. Error means the alarm rang because of human error or some mistakes. Inevitable means the alarm cannot be avoided. For instance, although T.S. Kaiwo Maru has 2 main engines and 2 propellers, it navigates with only one engine and one propeller due to slow steaming and diminishing fuel consumption. This slow steaming voyage keeps the ship's engine stall condition for one side of the engine plant. In regard to the category of abnormal alarms, actual abnormal alarms occurred an average of 3 times a day; however, only 8 alarms indicated a severe situation which affected the navigation schedule. These 8 alarms related to the high torque of the propeller shaft as mentioned above in case of actual "remedial plant operation". These 8 alarms rang in 2.5 hours. 


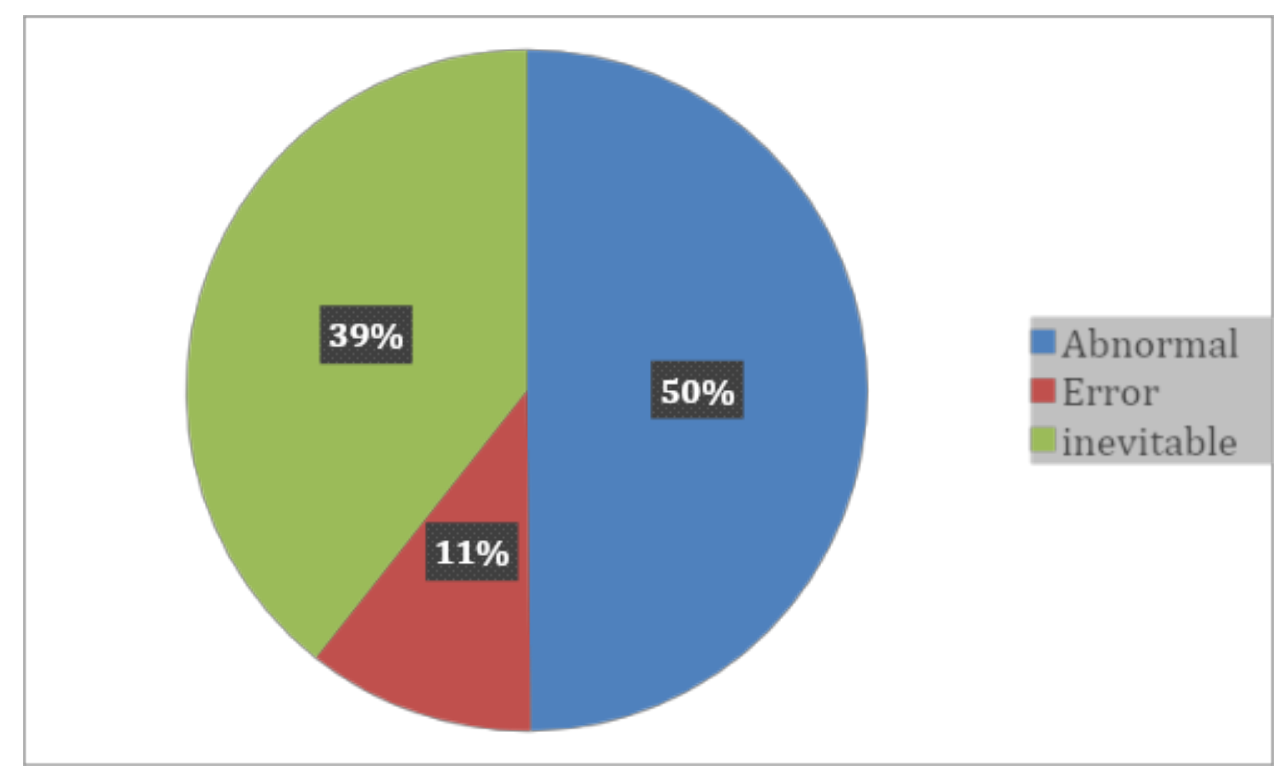

Figure 2. Type of alarms

\section{Future aspects for operational work relating to MASS}

Before conducting periodic unmanned engine room mode, the duty engineer and rating need to complete a checklist which takes much time. In case of degree 3 or 4 of MASS, the engineering crew must complete a much longer checklist. Moreover, numerous sensors and detectors will be equipped in order to monitor the condition of the machinery. In addition, everything will be operated remotely. Thus, from the engineering point of view, redundancy is one of the most important aspects for safety operation. Almost all machinery has spares on standby for starting immediately without any deficiencies in the system; therefore, manual operation systems or equipment should also be always utilized by engineering staff. In this way, more redundancy for full remote operation will be needed. Without further digitalization, degree 3 or 4 of MASS could hardly navigate a seagoing voyage because every parameter of the whole plant system should be detectable. Otherwise, full remote operation relating to engine plant operation would seldom succeed.

\section{Future aspects for maintenance work relating to MASS}

As far as automation systems for engineers' operational work are concerned, periodically unmanned engine room systems have been used successfully in seagoing vessels. As such, from a marine engineering point of view, with relation to degrees 1 and 2 of MASS, we can hardly find the need for additional knowledge and skills. However, taking into account engineers' daily maintenance work and remedial work for plant operation, fully unmanned engine room systems, such as degrees 3 and 4 of MASS will require maintenance work to be conducted remotely. According to Figure 1, CBM and BM occupied more than $40 \%$ of total work. With respect to $\mathrm{CBM}$ and $\mathrm{BM}$, machinery symptoms can rarely be predicted in advance. To deal with CBM and BM, future engineers would require more knowledge and skills relating to big data, artificial intelligence and robotics.

\section{Conclusion}

In this paper, based upon the 30 year old vessel, we categorized 592 alarms and 556 works during a 91 day voyage, including 38 days at sea, 14 days at anchorage and 39 days in port. 
Sensors detect temperature, pressure, level and signal both electrically and by air; therefore, control systems inform us by way of alarms when something is wrong in the system. However, engineering crews identified some deficiencies through their observation. Owing to automations such as unmanned engine room systems, electronic governors and auto load control systems for the main engine, engineering staff has been relieved from manual operation of the engine plant. However numerical data prove how often engineering staff deal with something wrong in the engine system. Taking into account the frequency of alarms and remedial work carried out by engineering crew as found by the study, we must utilize robotics for remote maintenance work, and AI and big data for monitoring. Thus, future marine engineers should acquire such new knowledge and skills. Otherwise, robotics engineers or AI engineers might be on board vessels when vessels of degree 3 or 4 of MASS are put in practice for seagoing voyages.

\section{References}

International Maritime Organization. (2019). Autonomous shipping. https://www.imo.org/en/MediaCentre/HotTopics/Pages/Autonomous-shipping.aspx 